\title{
COMPARISON OF THE LAUGHLEN REACTION FOR SYPHILIS WITH THE WASSERMANN AND KAHN REACTIONS
}

\author{
By C. RICKWORD LANE, D.M. \\ Maj., R.A.M.C.
}

In 1935 Laughlen described a rapid agglutination test for syphilis using an alcoholic antigen prepared in a way similar to that of the ordinary Kahn antigen but modified by the addition of a fat stain and of compound tincture of benzoin. For use it was diluted with 1.5 per cent saline. The sensitivity was adjusted by means of an electrolyte. This antigen was active for about three weeks if kept at room temperature in the dark, in hard glass containers. Since then several modifications have appeared-one by Laughlen in 1938, another by Walters in 1939, and a third by Tulloch (unpublished).

An investigation of the reaction was begun in 1938 but it had to be abandoned at the beginning of the war and an opportunity for continuing this work has only recently presented itself. Through the courtesy of Professor W. J. Tulloch details of his modification have been obtained. Antigen prepared by his method proved satisfactory, but difficulty was experienced with some batches owing to oversensitivity and the saline antigen could not be kept effective for longer than about three weeks. To overcome these difficulties the use of buffered saline was tried. Buffering at $p \mathrm{H} \mathbf{7 \cdot 2}$ proved to be most satisfactory. In addition, in the tests described, Army Presumptive Kahn antigen has been used instead of ordinary Army Kahn Antigen because it seemed to produce a more stable antigen without much alteration in its sensitivity.

\section{Preparation and use of the antigen}

The following method of preparation of the antigen was selected.

Take 20 millilitres of a buffer solution made up as follows : 48.5 millilitres of $M / 15$ $\mathrm{Na}_{2} \mathrm{HPO}_{4}, 11.5$ millilitres of $\mathrm{M} / 15 \mathrm{KH}_{2} \mathrm{PO}_{4}, 0.9$ gramme of A.R. sodium chloride.

The sodium chloride reduces the $p \mathrm{H}$ of the buffer solution from $7 \cdot 4$ to $7 \cdot 2$. Place the 20 millilitres of buffered saline in a universal container with a silver paper or Cellophane liner to the rubber of the screw cap ; place this container in a water bath at exactly $50^{\circ} \mathrm{C}$. In another container place 2 millilitres of Army Presumptive Kahn antigen, not more than six months old and of known satisfactory antigenic properties ; add a knife point of Scharlach R. or Sudan III ; screw down the cap, which should also be protected with silver paper or Cellophane. Do not shake to dissolve but place in the water bath at $50^{\circ} \mathrm{C}$. When the temperature of both fluids has reached $50^{\circ} \mathrm{C}$. remove the alcoholic antigen container, shake it to dissolve the fat stain, and add 16 drops of compound tincture of benzoin (using a Pasteur pipette cut off in the 56 hole in a standard wire gauge), swirl to mix and replace in the bath for a few seconds. Next remove both bottles, unscrew the caps, pour the buffered saline into the antigen rapidly and pour back and forth at least six times. The saline antigen is now allowed to stand for a short while and the supernatant fluid is decanted to get rid of particles of undissolved stain. After cooling to room temperature it is stored in the refrigerator in one of the universal containers and is ready for use in twenty-four hours.

If the antigen is satisfactory, flocculation should not occur and there should be very little sedimentation; complete sedimentation does not occur even after the antigen has stood for several days in the refrigerator. For use, the antigen is brought to room temperature.

\section{Carrying out the test}

The actual test is conducted in the following manner. The serums to be tested are inactivated at $56^{\circ} \mathrm{C}$. for thirty minutes. Although serums which have not been inactivated will in most cases give satisfactory results, occasionally a positive reaction will not be given when it is expected. One drop of each serum to be tested (using a 56 standard wire gauge dropper, mounted in a Cole's automatic pipette) is placed in the depression of a white porcelain tile. The pipette is rinsed through first with water and then with saline; the outside is wiped on filter paper and the pipette is then washed through with a little of the next serum. The 
washings pass right through into the reservoir which is emptied from time to time ; a drop of spirit in the reservoir prevents frothing. Serum is now taken up into the pipette and a drop placed in the next depression, the washing repeated and so on, until forty-eight serums have been pipetted. To each drop of serum is now added one drop of the antigen (using a 56 standard wire gauge Pasteur pipette). Mixing is accomplished by a few sharp taps on the side of each tile and the tiles are placed on a shaker going at about eighty shakes per minute and with a degree of violence just insufficient to cause the mixtures to come out of the depressions. Rocking rather than shaking by hand may replace mechanical shaking. Shaking is continued for ten minutes and the results are read at the end of this period. To prevent drying before shaking, tiles with twelve depressions are used and the tiles are stacked one on top of another, the filled tiles being placed underneath.

The results are inspected in a good light with the aid of a watchmaker's lens giving about a twofold magnification. With a good antigen all serums showing particles at this magnification are recorded as positive or doubtful. If no particles can 'be detected the result is recorded as negative. Occasionally a serum giving a strongly positive Wassermann reaction will be read as negative with this test if naked eye vision is relied upon. Serums having particles which can only just be seen through the lens are recorded as doubtful. The use at all stages of a standard dropper of suitable size is stressed; the loose description of the term, drop, without specification as to the size, which is used in some of the published methods, is deprecated.

\section{Laughlen reaction compared with the Wassermann and Kahn reactions}

Two thousand, one hundred and four serums have been investigated by the three tests-Laughlen, Wassermann and Kahn. The results are tabulated in Tables 1 and 2.

TABLE 1.-SUMMARY OF THE RESULTS WITH 2,104 SERUMS WITH THE THREE TESTS

\begin{tabular}{|c|c|c|c|c|c|}
\hline $\begin{array}{l}\text { WASSERMANN } \\
\qquad \begin{array}{c}+ \\
\text { D } \\
\text { D }\end{array}\end{array}$ & $\begin{array}{c}\text { KAHN } \\
\frac{1}{+} \\
+ \\
\text { D }\end{array}$ & $\begin{array}{c}\text { LAUGHLEN } \\
\begin{array}{c}+ \\
+ \\
+\end{array}\end{array}$ & $\begin{array}{c}\text { NUMBER OF } \\
1,611 \\
196 \\
22 \\
3\end{array}$ & $\begin{array}{l}\text { SERUMS } \\
\begin{array}{c}1,832 \\
(87 \cdot 1 \text { per } \\
\text { cent })\end{array}\end{array}$ & $\begin{array}{l}\text { Serums showing absolute } \\
\text { agreement in all three } \\
\text { tests }\end{array}$ \\
\hline - & $\begin{array}{l}+ \\
\mathbf{D}\end{array}$ & $\begin{array}{l}+ \\
+ \\
\mathbf{D}\end{array}$ & $\begin{array}{r}70 \\
35 \\
6\end{array}$ & $\begin{array}{l}111 \\
\left(5 \cdot 2_{\text {cent }}\right)\end{array}$ & $\begin{array}{l}\text { Serums showing relative } \\
\text { agreement in Kahn- } \\
\text { Laughlen }\end{array}$ \\
\hline$\frac{\bar{t}}{\bar{D}}$ & $\begin{array}{l}\overline{+} \\
\bar{D} \\
+ \\
D\end{array}$ & $\begin{array}{l}\frac{+}{D} \\
\text { - }\end{array}$ & $\begin{array}{r}113 \\
1 \\
30 \\
13 \\
3 \\
1\end{array}$ & $\begin{array}{l}\left(7 \cdot 7^{161} \mathrm{per}\right. \\
\text { cent }\end{array}$ & $\begin{array}{l}\text { Serums showing disaagree- } \\
\text { ment } \\
\text { (see Table 2) }\end{array}$ \\
\hline & & Total & 2,104 & 2,104 & \\
\hline
\end{tabular}

$+=$ Fully positive $;-=$ Fully negative $; \mathbf{D}=$ Doubtful.

TABLE 2.-SERUMS SHOWING COMPLETELY DISCORDANT RESULTS IN THE THREE TESTS WITH CLINICAL DETAILS

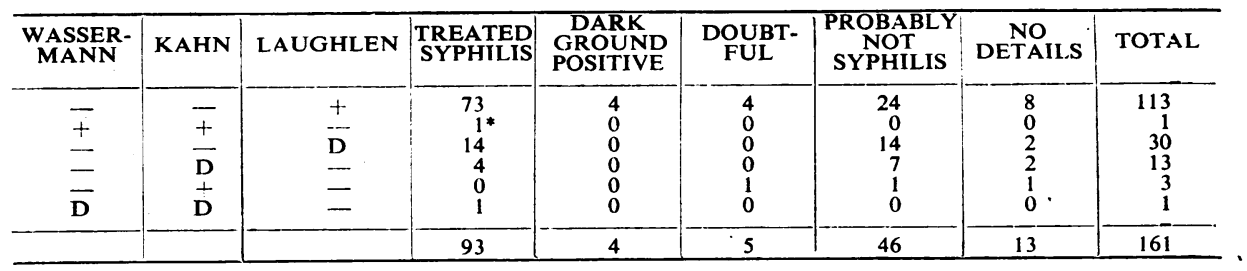

* This serum was very bile-stained

Of the 2,104 serums examined 493 gave positive or doubtful results in one or more of the above tests and of these, 429 were from known cases of treated or untreated syphilis. In the latter group of 429 serums, 423 had a positive or doubtful result 
in the Laughlen test, i.e. 98.6 per cent. Assuming that all the serums giving negative results in all three tests were from uninfected or cured patients and that all those labelled as probably not infected with syphilis, together with those from whom details could not be obtainèd, were in fact negative, 1,670 serums should have given negative results; of these a positive or doubtful Laughlen was obtained in 48 or 2.9 per cent of false positives.

Only one serum which gave frankly positive Wassermann and Kahn reactions gave a negative Laughlen reaction ; this serum was very deeply jaundiced. Bilestaining may make results difficult to read; however, the reading can always be made with the aid of the lens. This serum, however, gave an undoubted negative result both when pure and when diluted with saline and had been obtained from an undoubted case of treated syphilis. Negative results on deeply jaundiced serums should therefore be accepted with caution. On the other hand, very considerable degrees of haemolysis in the serum do not interfere with the test. One serum giving doubtful Wassermann and Kahn reactions gave a negative Laughlen reaction and this serum also was from an undoubted case of treated syphilis. Apart from these, 3 serums gave positive Kahn reactions but negative Laughlen reactions; one of these was from a doubtful case of syphilis, another was probably not syphilitic and of the third details could not be obtained. Thirteen serums gave doubtful Kahn reactions and negative Laughlen reactions; 4 were from cases of treated syphilis, 7 were probably from non-syphilitic cases, and of 2 details could not be obtained.

It will be seen that if the result on the deeply bile-stained serum be excluded, the Laughlen test has not contradicted a single frankly positive Wassermann result ; only one serum giving a doubtful positive Wassermann reaction and from an undoubted treated case of syphilis has given a negative result in the course of the - examination of 2,104 serums. This is regarded as a highly satisfactory result.

The 2.9 per cent of false positive results are not considered at all unsatisfactory for a test that is recommended only as a highly sensitive screen.

\section{Advantages of the Laughlen test}

The Laughlen test has been recommended as a means whereby the physician can make a diagnosis of syphilis " in his office". But it is felt that there cannot be any such short cut to the serological diagnosis of syphilis. All precipitation tests tend to exhibit prozones, positive serums at a certain level giving negative results, whereas a perfectly satisfactory result may be obtained with serums of both higher and lower reagin content than the critical level. In addition different precipitation tests commonly give false negative results, due to prozones at levels different from each other. The use, therefore, of two different precipitation tests or the use of more than one dilution of serum or antigen in a single test may overcome this defect. Both these procedures raise technical difficulties for a clinical side-room test. Again there are invariably slight differences in batches of antigen and reliability can be achieved only when a reasonably large number of serums are being examined so that constant comparison with another test can be maintained and when adequate running controls can be included.

\section{Conclusions}

In a laboratory, in which both Wassermann and precipitation reactions are carried out and the numbers dealt with are large, a sensitive screen saves much time. All serums are tested with the screen test and with a one-tube Wassermann method. Positives by either method are then picked out and put through the complete Wassermann reaction and the three-tube ordinary Kahn test ; serums negative to both preliminary tests are accepted as negative. In the past the Presumptive Kahn test has been used in this manner but it has taken a longer time. When a very quick result is required the modified Laughlen test can be set up at any time, since the antigen is stable and the result to be checked later will have a high degree of probable accuracy. Neither the Presumptive Kahn test, which gives false positives due to prozones, nor the Laughlen test should be used as a single 
test for syphilis either in a negative or a positive sense. It is probable, however, that a combination of these two tests could be used, without any other aids, as a rapid means of excluding syphilis, because the false negatives of each would be revealed by the other. Excluding the separation and inactivation of the serums 144 specimens can be examined from beginning to end by one person in one-half to three-quarters of an hour. It has been stated that the antigen keeps well. This opinion is based on a comparison of the results with those of the Wassermann and Kahn reactions with antigens of different age, and on the results of a series of twenty-two picked serums which gave exactly the same results with a three months' old and a two days' old antigen.

\section{Summary}

(1) A modification of the Laughlen reaction using buffered saline is described.

(2) The method of preparation and use of the antigen is detailed.

(3) A comparison of the modified Laughlen, Wassermann and Kahn reactions on 2,104 serums is tabulated.

(4) The advantages of the use of this test as a sensitive screen are discussed.

\section{REFERENCES}

Laughlen, G. F. (1935) Canad. med. Ass. J., 33, 179.

- (1938) Canad. publ. Hlth J., 29, 396.

Walters, A. H. (1939) Brit. J. vener. Dis., 15, 228.

\section{CORRESPONDENCE}

\section{GONOCOCCAL FIXATION TEST}

Sir,--In Dr. Harkness's article entitled 'Drug Resistance in Gonorrhoea', I note he makes the following statement ' $\ldots$ indeed a positive reaction (G.C.F.T.) is useless as a test of cure'. I presume that what he means is that if, during a test of cure, the G.C.F.T. is found to be positive, it is of no significance.

If this be true, it limits the value of this test considerably, and therefore it behoves Dr. Harkness to produce concrete evidence in support of his contention.

If, on the other hand, his contention is merely a pious hope based on intuition, and useful as a means of disregarding, Nelson-wise, an inconveniently positive G.C.F.T., it seems a pity that he should ever have given voice, in no uncertain way, to such an opinion. It can but lead astray the unwary and do much harm in making confusion worse confounded in the minds of the many for whom some are striving to evolve a reasonable test of cure for gonorrhoea.

London, W.1

I. N. ORPWOOD PRICE

Sir,- In his letter which appears above, Dr. I. N. Orpwood Price paraphrases a statement of mine on the gonococcal fixation test (G.C.F.T.) that if, during a test for cure, the G.C.F.T. is found to be positive, it is of no significance. He goes on to challenge me to produce concrete evidence in support of this contention. Here it is.

For many years this test has been carried out on all my patients suffering from venereal diseases, and during the last seven years Dr. Price himself has performed them on the majority of my private patients and on a small number attending me at hospital. My experience, therefore, extends over a number of years and if I were asked to discard one test, clinical or pathological, used in any stage of the disease, I should have no hesitation in saying that it would be the complement fixation test.

It is generally agreed that the complement fixation reaction for gonorrhoea registers the presence or absence of specific antibodies, but does not signify the presence or absence of gonococci in the tissues. It is interesting to note that in 1935 Dr. Price was maintaining that a positive test, provided no vaccine had been administered, was always indicative of the presence of living gonococci in the tissues, but that in 1938 he was not quite so dogmatic and considered that it was almost always the case.

This test, depending as it does on circulating antibodies, has become even more meaningless since the advent of sulphonamide therapy, which effects a rapid cure in a large majority of cases. Chemotherapy (in adequate dosage) prescribed early in the disease usually cures the infection before the blood becomes positive and the blood remains negative throughout the period of observation; but in the cases in which treatment is delayed for a week or longer it often becomes positive, and the longer the delay the more likely is it to remain positive after a cure has been effected. The clinician's only difficulties are in the small percentage of failures which are invariably occasioned by drug resistance, associated very rarely with closed foci of infection. In my experience negative results are always obtained when the resistance is 'partial' and often (and this may be 